\title{
The Summary of the Thermal Protection Test Technology Using High Temperature and Supersonic Gas Jet
}

\author{
Qi Bin ${ }^{1,2, *}$, Tian Ning ${ }^{2}$, Zou Yanghui ${ }^{2}$, Zhang Lisong ${ }^{2}$ and Lou Wenzhong ${ }^{1}$ \\ ${ }^{1}$ Beijing Institute of Technology, Beijing 100081, China \\ ${ }^{2}$ Beijing Institute of Space Long March Vehicle, Beijing 100076, China
}

\begin{abstract}
The thermal protection test can be done by high temperature and supersonic gas jet, which plays an important role in promoting global thermal protection system development over the past few decades. The principle, characteristics and applications of the test method are presented. Furthermore, the development of thermal protection technology for high supersonic air vehicle in the future is analyzed, and how to adapt the aforementioned development for gas jet test is suggested accordingly.
\end{abstract}

\section{Introduction}

High supersonic air vehicle is faced with intense aerodynamic heating load during flying in the atmosphere. Temperature on aircraft stagnation point or leading edge surface can be up to several thousand degrees and even higher. Different temperature distributions are formed for large area. High temperature ablation, thermal structure, thermal sealing, long-term thermal insulation and other problems are significant. Once thermal protection system is failed, aircraft overheating, structure failure and even collapse in the air can be caused as a result. Therefore, thermal protection technology is one of primary and key technical problems that should be solved by high supersonic air vehicle research at all generations.

Research and assessment on thermal protection technical solution by ground test is the most important and the most effective means during research and development of high supersonic air vehicle thermal protection system [1, 2]. Corresponding test equipment is established in the United States, Russia, Japan, Europe and China for carrying out relevant test [3-5]. Gas jet heater/wind tunnel and electric arc heater/wind tunnel are mainly adopted in China and foreign country as main equipment for thermal protection technology research and project assessment [6, 7]. These two kinds of equipment coexist for long term in the United States, Russia (former Soviet) and China.

High temperature gas jet test is regarded as one of the most important thermal protection test appraisal means, which provides strong guarantee for research and development of thermal protection system. It plays an important supporting role in thermal protection technology development and key technology breakthrough. In the paper, gas jet test basic principle, characteristics and main application situation at home and abroad are introduced. Improvement and updating of gas jet test equipment and technology are analyzed aiming at future development direction and demand of thermal protection system.

\section{Gas Jet Test Principle and Characteristics}

It is generally difficult to simulate gas parameters of high Mach number under actual flight condition in ground thermal protection assessment tests. Air flow with high temperature, high enthalpy and low Mach number is often used for achieving similar aerodynamic heating effect. Principles of liquid rocket engine are usually used as reference of gas jet thermal protection test. Fuel is combusted in the main heater combustion room for generating high temperature and high pressure gas source. A bunch of high temperature supersonic gas jet is formed through acceleration by supersonic nozzle for thermal protection test assessment on thermal protection materials or components.

Design and optimization goals of gas main heater for thermal protection test are different from liquid rocket engine for boosting. When liquid rocket engine is designed, total thrust, specific thrust, proportion and other parameters are mainly considered. When gas main heater is designed, thermal environment experiment ability of gas jet formation is mainly considered. They are different in the aspects of main heater organization combustion mode, combustion process, nozzle profile design, thermal protection design, etc., thereby controlling spout external flow field boundary layer thickness, uniformity and flow field form, finally formed heat flow size, and regulating the flow field state in certain scope.

Principles of gas jet test are shown in figure 1.

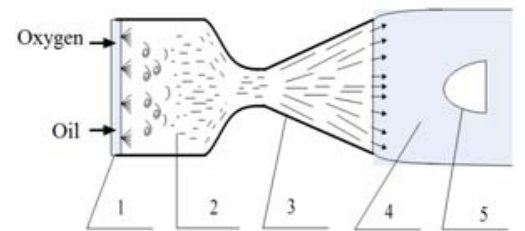

1-injector; 2-combustion chamber; 3-nozzle; 4-gas jet;5-test model

Figure 1. The sketch of thermal protection test using gas jet

Thermal protection assessment test is mainly related to heat flux, temperature, gross heating value, enthalpy, pressure, shear force and other simulation parameters. However, it is difficult to simulate many parameters in ground test synchronously. Simulation parameters should 
be selected in gas jet test according to different test objects and purposes. Heat flux and gross heating value are commonly used as the first simulation parameters, while enthalpy, pressure, shear strength and other parameters are regarded as reference. Testers can obtain and assess whether gas jet can meet test condition requirements or not through cold wall heat flux, surface pressure, enthalpy and other test models. Simulation and assessment of shear force should be considered for assessment test requiring consideration of material erosion or abrasion resistance tests. Since gas jet composition and properties are different from air medium, especially for thermal protection composite material in carbon base class more sensitive to oxidation medium in the flow field, difference under the test condition should be considered and analyzed.

Gas total temperature range is generally $3000 \mathrm{~K}$ to $3600 \mathrm{~K}$ on main heater outlet aiming at gas main heater with gas oxygen and kerosene as fuel. Gas static temperature range at the outlet is generally $1400 \mathrm{~K}$ to $2600 \mathrm{~K}$, which is associated with outlet Mach number; Gas total enthalpy at the outlet is commonly $7000 \mathrm{KJ} / \mathrm{kg}$ to $9000 \mathrm{KJ} / \mathrm{kg}$. Heat flux scope generally realized in gas jet test is $1000 \mathrm{KW} / \mathrm{m} 2 \sim 15000 \mathrm{KW} / \mathrm{m} 2$ aiming at plane thermal protection test. Heat flux scope generally realized in gas jet test is $10000 \mathrm{KW} / \mathrm{m} 2 \sim 40000 \mathrm{KW} / \mathrm{m} 2$ aiming at end and front edging thermal protection test, which is related to specific end radius. Required thermal environment [8] can be obtained through adjusting gas main heating working condition, choosing different nozzles, and adjusting relative positions of model and gas flow.

A few hundred megawatt magnitude can be realized for large size model thermal structure test. It has important significance for overall or most section 1: 1 thermal protection assessment. It is not limited by external conditions, and test can be implemented at any time. Chemical energy also has advantages in the aspect of test operation cost.

\section{Domestic And Foreign Gas Jet Test Systems And Their Application}

\subsection{Foreign gas jet test equipment}

Foreign countries attached great importance to gas jet test equipment construction since 1950s. Typical equipment includes Combustion-Heated Scramjet Test Facility (CHSTF) and 8 feet high temperature wind tunnel of American Langley Center, Japan NAL hypersonic wind tunnel, Russian $\mathrm{Y}$-306-3 hypersonic wind tunnel, etc.

8 feet wind tunnel of American Langley Center plays an important role in developing thermal protection technology of high supersonic air vehicle[9-11]. It belongs to a gas jet hypersonic wind tunnel with air and methane as fuel. It can provide high altitude flight simulation environment with Mach number of 4, 5, 7 and height of $15.24 \mathrm{~km}$ to $36.6 \mathrm{~km}$. Wind tunnel structure is shown in figure 2. Nozzle diameter in the test section is
$2.4 \mathrm{~m}$ (8 feet), length is $3.66 \mathrm{~m}$ (12 feet), and stability test time can reach $60 \mathrm{~s}$.

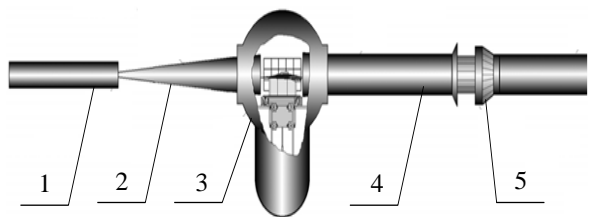

1-combuster; 2-nozzle; 3-test cabin; 4-diffuser; 5-air ejector

Figure 2. The sketch of 8-Ft. HTT

The typical test state parameters are shown in the following table 1.

Table 1. 8-Ft. HTT status

\begin{tabular}{|c|c|c|c|c|}
\hline Mach number & 4 & 5 & 5 & 7 \\
\hline Outlet diameter (m) & 2.4 & 2.4 & 1.4 & 2.4 \\
\hline stagnation point P(psia) & 85 & 285 & 549 & 2000 \\
\hline stagnation point T(R) & 1670 & 2072 & 2145 & 3480 \\
\hline $\begin{array}{c}\text { Dynamic pressure of } \\
\text { nozzle spout (psf) }\end{array}$ & 1323 & 1228 & 2071 & 1273 \\
\hline Simulated height(kft) & 66 & 72 & 62 & 85 \\
\hline
\end{tabular}

8-Ft. HTT supported the investigation project in 1966 and hypersonic engine thermal structure match research project in 1977 successively. Basic experimental study on hypersoni aerodynamic problems and aerodynamic thermal structure was implemented. 8-Ft. HTT supported experimental study of thermal protection system (TPS) of round-trip flight vehicle project in the 1970s, which also supported X - 24C project for thermal sealing test and other research. The equipment was used for experimental research on stagnation zone structure and material of reentry vehicle and advanced missile warhead in the late $1970 \mathrm{~s}$ and early 1980s. Concept demonstration engine test of hydrogen fuel in national space shuttle program (NASP) was successfully implemented for the first time in June 1994. 8-Ft. HTT started to support X-33 project after NASP project. The unique test ability was used for simulating flight aerodynamic heating conditions faced by X - 33 thermal protection system. Thermal protection system test assessment of X-33 was completed in 1998. After 8-Ft. HTT was constructed, it has become the most effective test equipment in America Langley Center in studying pneumatic heat basis problem, thermal protection test and hypersonic propulsion system test, and other similar test facilities are gradually phased out.

RJTF wind tunnel of Japan National Space Lab belongs to a jet wind tunnel with simulated altitude of 20 $\sim 35 \mathrm{~km}$ and Mach number of $4 \sim 8$, which is composed of energy-storage air heater (SAH), gas mixed heater (VAH), nozzle, test cabin, diffuser, injector, etc.

Table 2. The status of RJTF

\begin{tabular}{|c|c|c|c|c|}
\hline Mach number & 8 & 6 & 6 & 4 \\
\hline Height $(\mathrm{Km})$ & 35 & 25 & 25 & 20 \\
\hline Heater & SAH+VAH & VAH & SAH & SAH \\
\hline Total T(K) & 2600 & 1660 & 1580 & 872 \\
\hline Total P $(\mathrm{MPa})$ & 10 & 4.78 & 5.25 & 0.86 \\
\hline Test time (s) & 30 & 60 & 60 & 60 \\
\hline
\end{tabular}




\subsection{Domestic gas jet test equipment}

Beijing Institute of Space Long March Vehicle started developing gas jet test equipment for thermal protection test since 1960. It cooperated with air power technology research institute to develop research on experimental flow field testing technology in 1990s. YA6804/06/14 series free jet gas jet test equipment was formed. High temperature gas supersonic wind tunnel test system with spout diameter at meter magnitude and total power higher than hundred megawatts is constructed currently. The above-mentioned gas jet test equipment played an important role in research and development of high supersonic air vehicle thermal protection products at the first and second generations in China. Figure 3 shows plane thermal protection model test on YA6804gas jet test equipment. Figure 4 shows cone cap thermal protection model test on YA6806gas jet test equipment.

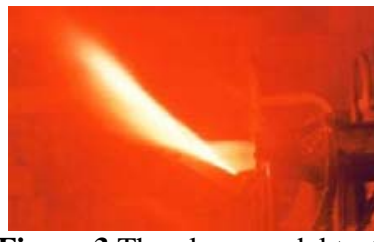

Figure 3.The plane model test on the YA6804 Facility

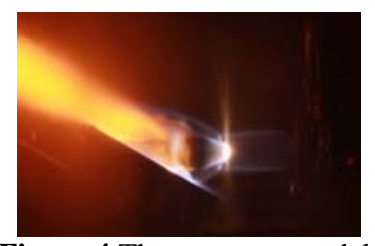

Figure 4.The cone cap model test on the YA6806 Facility
Main structure of YA200 high temperature gas jet supersonic wind tunnel test system is shown in the following figure, which is mainly composed of main heater, test cabin, diffuser, cooling exhaust system, etc. In addition, the system also includes energy system, piping system, measurement and control system, etc. supporting wind tunnel main body. Oxygen and aviation kerosene are combusted in main heater, high temperature and high pressure gas is produced, which is accelerated by supersonic nozzle for forming high temperature supersonic gas jet meeting assessment test requirements. The test model is assessed in the test cabin. The abovementioned gas is discharged into diffuser for deceleration and pressurization, which is discharged after being cooled by cooling exhaust system.

Typical test state parameters of the above gas jet test equipment are shown in the following table 3.

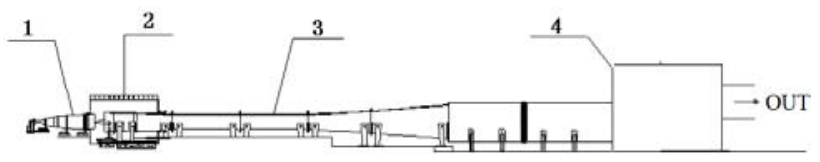

1-main heater and nozzle; 2-test cabin; 3-diffuser; 4coolingexhaust device

Figure 9.The sketch of YA200
Table3. Main performance parameters of gas jet test equipment

\begin{tabular}{|c|c|c|c|c|}
\hline Equipment & YA6804 & YA6806 & YA6814 & YA200 \\
\hline Type & Free jet & Free jet & Free jet & $\begin{array}{c}\text { Wind } \\
\text { tunnel }\end{array}$ \\
\hline Total T (K) & 3470 & 3650 & 3650 & 3650 \\
\hline Static T (K) & 2210 & 2185 & 2596 & $\begin{array}{c}1500- \\
2600\end{array}$ \\
\hline Mach & 2.4 & 3 & 3 & $2.8-4.2$ \\
\hline $\begin{array}{c}\text { Nozzle } \\
\text { diameter } \\
\text { (mm) }\end{array}$ & 65 & 70 & 167 & $340-1500$ \\
\hline $\begin{array}{c}\text { Main } \\
\text { purposes }\end{array}$ & $\begin{array}{c}\text { Ablation and } \\
\text { thermal } \\
\text { protection } \\
\text { performance } \\
\text { assessment }\end{array}$ & $\begin{array}{c}\text { Ablation and } \\
\text { thermal } \\
\text { protection } \\
\text { performance } \\
\text { assessment }\end{array}$ & $\begin{array}{c}\text { Ablation } \\
\text { and local } \\
\text { thermal } \\
\text { structure } \\
\text { assessment }\end{array}$ & $\begin{array}{c}\text { Large- } \\
\text { dimension } \\
\text { thermal } \\
\text { structure } \\
\text { assessment }\end{array}$ \\
\hline
\end{tabular}

\section{Demand Of Future Thermal Protection Technology Development On Gas Jet Test}

In recent years, military powers represented by the United States have carried out a large amount of work and made significant achievements in orbit return, near space and other fields, such as operational prototype of conventional attack missile (CSM) plan under United States rapid global combat system, namely boost-glide high supersonic air vehicle HTV-2 [12]; high reliability and reusable unmanned space testing machine Developed by U.S. Air Force, namely orbital test vehicle (OTV) X37B [13], and hypersonic cruise missile demonstration project X - 51A [14] jointly implemented by U.S. Air Force and National Defense Advance Research Projects Agency (DARPA) .

Currently, high supersonic air vehicle is developed from traditional ballistic reentry flight vehicle to direction of motorized and multi-space hierarchy aircraft. Representative types include aerospace vehicle, nearspace vehicle, orbit return flight vehicle, suborbital vehicle, etc. Aerodynamic heating load bearing time of flight vehicle in new generation is prominently increased compared with previous vehicles. Thermal flow environment faced by thermal protection components in different parts at different flight trajectories is changed from dozens to tens of thousands of kilowatts per square meter. Asymmetric and special shape aerodynamic heating problems are highlighted. Thermal environment is very complex. Aerodynamic heating and thermal protection technology thereof face major challenges, which are listed as three key technologies of new generation flight vehicle development with hypersonic aerodynamics and guidance control.

In thermal protection technology, technical difficulties of non-ablation or low ablation and thermal insulation of thermal protection materials should be solved on one hand, thermal structure and thermal matching problems of different parts and different components as well as mutual thermal structure and thermal matching problems also should be solved on the other hand. It is a brand-new design concept [15-16] compared with thermal protection design of previous vehicles. Higher requirements are proposed on thermal protection system design capability and ground test 
assessment ability of thermal protection plan due to the above characteristics. When design means are updated and optimized, gas jet test technology also requires corresponding technology reserves and development as one of important means supporting thermal protection technology research.

1) Various performance assessments of thermal protection materials, especially multilayer composite heat protection and insulation structure materials, should be completed in order to simulate continuous large-extent change of aerodynamic heating load. State and thermal environment adjustment in the test process should be realized in ground test. Gas jet test equipment can realize change of thermal flow from seven hundreds to thousands of kilowatts per square meter through introducing component mixing technology for adjusting state. Radiation heating equipment should be configured for supplementing thermal flow change scope from dozens to hundreds of kilowatts per square meter in necessary condition. Long-term whole-journey thermal environment simulation test ability can be formed;

2) Scale of parts with prominent thermal stress is not very big aiming at structure model in traditional cone column combined class. However, emphasized part size should be much bigger aiming at flight vehicle in new generation with complex structure appearance. Large-size thermal structure test must be carried out for thermal structure, thermal sealing and thermal matching tests under overall or local structure 1:1 condition. Ground test assessment must be provided with long-time (more than one hundred seconds), large size (effective assessment section is above meter magnitude) and high power (more than several hundred megawatts) ability in order to realize the above experiment ability.

3) Research level of related test theory, test and analysis technology should be continuously improved. Thermal protection system fine design should be supported by more accurate test data. Basic problems in the test should be theoretically studied and tested. Accurate measurement of model surface temperature under gas coating condition and surface chemical reaction condition, gas composition measurement, enthalpy value measurement, long-term model surface thermal flow density and shear force measurement under high temperature supersonic condition, and other test analysis abilities should be solved and improved.

\section{Summary}

Gas jet test technology provides important support for developing domestic and foreign hypersonic vehicle thermal protection technology. In the paper, principles and features of gas jet for thermal protection test are introduced. Domestic and foreign similar gas jet test equipment and application conditions thereof are investigated. It is proposed that long-term, high power and adjustable state are development direction of subsequent gas jet test system according to vehicle thermal protection and insulation technology development trend as well as its demand on ground thermal protection and insulation test in the future.
Meanwhile, corresponding test experiment and analysis technology should be developed, therefore gas jet test technology can play greater role in studying future supersonic vehicle in China.

\section{References}

[1] Laub B., Balboni J. and Goldstein H. Ground Test Facilities for TPS Development. NASA T M-2002211400, NASA Ames Research Center, Moffett Field, California, May 2002.

[2] Jay H. Grinstead, George A. Raiche. Test Engineering for Arc Jet Testing of Thermal Protection Systems: Design, Analysis, and Validation Methodologies. AIAA 2006-3290.

[3] S.F. Harvin and K.F. Cabell. Test Capability Enhancements To The NASA LANGLEY 8-Foot High Temperature Tunnel. NASA 20070003589.

[4] G.Russo. The Scirocco Wind Tunnel Project: Progress Report 1993. 1993, AIAA-93-5117.

[5] Edwin P. Russo. NASA's John C. Stennis Space Center High Heat Flux Facility. AIAA-96-2209.

[6] D. M. Smith and E. J. Felderman. Aerothermal Testing of Space and Missile Materials in the Arnold Engineering Development Center Arc Jet Facilities.AIAA 2006-3293

[7] B. Laub. Use of Arc-Jet Facilities in the Design and Development of Thermal Protection Systems.AIAA 2006-3292

[8] Qi bin, Lou Wen-zhong, Tian Ning. The Thermalenvironment Analysis of High Temperature and Supersonic Flow Field for Thermal Protection System Test.Aerospace Material \& Technology, 2014,44(5) :30-35.

[9] Jeffrey S. Hodge and Stephen F. Harvin. Test Capabilities and Recent Experiences in the NASA Langley 8foot HTST. AIAA 2000-2646

[10] James Wayne Sawyer, Jefferson Flodgc, Brad Moore. Aerothermal Test OF METALLIC TPS For x-33 in 8ft HTST. NASA20040100700

[11] James Wayne Sawyer, Jefferson Hodge, Brad Moore. Aerothermal Test of Thermal Protection Systems For X-33 Reusable Launch Vehicle. NASA20040086762

[12]Dr. Steven H. Walker, Lt. Col Jeffrey Sherk. The DARPA/AF Falcon Program: The Hypersonic Technology Vehicle \#2 (HTV-2) Flight Demonstration Phase. AIAA 2008-2539

[13] Arthur C. Grantz1. X-37B Orbital Test Vehicle and Derivatives. AIAA 2011-7315

[14]Graham G raham Candler, Heath Johnson, Christopher Alba. Analysis of Modal Growth on the Leeward Centerplane of the X-51 Vehicle. ADA513296.2009

[15]Liang Bo,Yi Jian-zheng,Zhou Zhi-qiang. General Situation and Development Trend of Aircraft Thermal Protection Research. Equipment Environmental Engineering, 2008, 5(04):41-44.

[16] Heppenheimer, Thomas A. Facing the Heat Barrier: A History of Hypersonics.NASA/SP-2007-4232. 